\title{
On the influence of solar activity on the mid-latitude sporadic E layer
}

\author{
Michael Pezzopane ${ }^{1, *}$, Alessio Pignalberi ${ }^{2,3}$, and Marco Pietrella ${ }^{1}$ \\ 1 Istituto Nazionale di Geofisica e Vulcanologia, Via di Vigna Murata 605, 00143 Rome, Italy \\ ${ }^{*}$ Corresponding author: michael.pezzopane@ingv.it \\ 2 Dipartimento di Ingegneria dell'Informazione, Elettronica e Telecomunicazioni, Sapienza Università di Roma, \\ 00185 Rome, Italy \\ 3 Istituto per la Scienza dell'Atmosfera e del Clima, CNR, 00133 Rome, Italy
}

Received 24 February 2015 / Accepted 27 July 2015

\section{ABSTRACT}

To investigate the influence of solar cycle variability on the sporadic E layer (Es), hourly measurements of the critical frequency of the Es ordinary mode of propagation, $f o E s$, and of the blanketing frequency of the Es layer, $f b E s$, recorded from January 1976 to December 2009 at the Rome (Italy) ionospheric station $\left(41.8^{\circ} \mathrm{N}, 12.5^{\circ} \mathrm{E}\right)$, were examined. The results are: (1) a high positive correlation between the F10.7 solar index and $f o$ Es as well as between F10.7 and $f b$ Es, both for the whole data set and for each solar cycle separately, the correlation between F10.7 and $f b$ Es being much higher than the one between F10.7 and $f o$ Es; (2) a decreasing long-term trend of the F10.7, $f o$ Es and $f b$ Es time series, with $f o$ Es decreasing more rapidly than F10.7 and $f b$ Es; (3) clear and statistically significant peaks at 11 years in the $f o$ Es and $f b E s$ time series, inferred from Lomb-Scargle periodograms.

Key words. Ionosphere (mid latitude) - Solar cycle - Data analysis - Radio sciences - Plasma physics

\section{Introduction}

Usually the term "sporadic-E layer" (Es) refers to ions and electrons confined within very thin layers $(0.6-2 \mathrm{~km})$, appearing at the ionospheric heights typical of the E region (95$120 \mathrm{~km}$ ), whose density can reach much higher values than those of the normal daytime E region. Es layers can seriously affect the HF and low-VHF communications, causing over the horizon propagation for signals otherwise restricted to line-ofsight (Rice et al. 2011). In the past years, the characteristics of mid-latitude Es layers have been extensively studied by many authors (see reviews by Whitehead 1970, 1989; Mathews 1998; Haldoupis 2011, 2012). The most accredited theory in explaining the formation of the Es layers is the vertical wind-shear theory, conceived in the 1960 s studies mostly associated with the atmospheric gravity waves (Whitehead 1961; Axford 1963; Chimonas \& Axford 1968). The main parameters on which this theory is based are: the concentration of the metallic ions of meteoric origin, the Earth's horizontal magnetic field component and the vertical wind shears of the neutral horizontal winds. The latter, thanks to a combined action of the ion-neutral collisional coupling and the geomagnetic Lorentz force, trigger the long-lived metallic ions produced by the continuous meteoric shower activity to move vertically into the convergence node of the neutral horizontal wind vertical profile, thus forming dense and narrow ionization layers. More specifically, it has been found that the appearance and intensity of mid-latitude Es layers is influenced by vertical wind shears related to tidal waves, gravity waves and planetary waves, that compel the metallic and molecular ions into thin layers at altitudes from 95 to $120 \mathrm{~km}$ (Chimonas 1971; MacDougall 1974; Wilkinson et al. 1992; Szuszczewicz et al. 1995; Tsunoda et al. 1998; Haldoupis \& Pancheva 2002; Haldoupis et al. 2004; Pignalberi et al. 2014, 2015).
In the last decades, many authors have investigated the influence of solar cycle on Es layer. The majority of works debated this issue in terms of Es occurrence percentages, with limiting varying values of the critical frequency of the Es ordinary mode of propagation (foEs) (Kotadia 1969; Baggaley 1984; Pietrella \& Bianchi 2009). Kotadia (1969), who considered less than half a solar cycle data, found a negative correlation between the Es occurrence and the solar activity. Baggaley (1984) while analysing data covering three solar cycles, that were recorded at two stations located in the southern hemisphere, found a positive correlation between the long-term occurrences of the blanketing frequency of Es layer ( $f b \mathrm{Es}$ ) and the Zurich sunspot number $R_{\mathrm{z}}$, but he did not find any correlation for $f o$ Es. More recently, also Pietrella \& Bianchi (2009), analysing data recorded at one mid-latitude station over three solar cycles, found no significant dependence of $f o$ Es occurrences on solar cycle variability. Pietrella et al. (2014), by using the same data set of Pietrella \& Bianchi (2009), showed also that, regardless of the solar activity, Es develops concurrently over extended regions in space, instead of being a spatially limited layer. Instead of considering the Es occurrence, Bossolasco \& Elena (1963) and Maksyutin et al. (2001) investigated this issue by analysing simply the foEs values. Bossolasco \& Elena (1963) used data recorded at several mid-latitude stations between 1958 and 1962 to show that higher yearly mean values of $f o$ Es occur generally with higher yearly mean sunspot numbers, and they proposed a basic analytical relation between these two quantities. Also Maksyutin et al. (2001), referring to data recorded at Moscow during three solar cycles, found that daytime yearly mean values of foEs are positively correlated with yearly mean sunspot numbers.

Nonetheless, Whitehead (1989) in his review paper says that in general $f o$ Es shows little variation with sunspot number, 
and long-term trends are apparently unrelated to solar activity. Hence, from the existing literature it emerges that this issue is still under debate.

The analyses described in this paper, that are based on $f o$ Es and $f b$ Es time series and not on Es occurrence percentages, are much more refined than those performed by Bossolasco \& Elena (1963), and by Maksyutin et al. (2001), and show unambiguously that the solar variability affects the Es layer.

The data set considered, how the data analysis has been carried out and the corresponding results are described in Section 2. The discussion of the results and the conclusions are the subject of Section 3.

\section{Data set, analysis and results}

The data set considered in this study is constituted by hourly values of $f o$ Es and $f b$ Es recorded at the ionospheric station of Rome $\left(41.8^{\circ} \mathrm{N}, 12.5^{\circ} \mathrm{E}\right)$, Italy, from January 1976 to December 2009, and validated according to the URSI (International Union of Radio Science) standard (Piggott \& Rawer 1972). Data were downloaded from the electronic Space Weather upper atmosphere (eSWua) database (http://www. eswua.ingv.it/) (Romano et al. 2008). As indicator of the solar activity the index $F_{10.7}$ is considered.

It must be pointed out that during the investigated period there was no change of ionosonde from the classical one to the DPS4 digisonde (Bibl \& Reinisch 1978), which could have led to a significant decrease of $f o$ Es average values (Lastovicka et al. 2012). The $f o$ Es values were all validated from traces recorded by classical ionosondes which cannot tag the different polarization of the two modes of propagation. A VOS-1 chirp ionosonde produced by the Barry Research Corporation, Palo Alto, CA, USA (Barry Research Corporation 1975) sounded from January 1976 to November 2004 and then it was replaced by an AIS-INGV ionosonde (Zuccheretti et al. 2003).

This means that the $f o$ Es and $f b$ Es validated time series considered in this study represent a reliable and homogeneous data set. Moreover, it is worth noting that it is rare to rely on validated $f o$ Es and $f b$ Es data recorded for more than three solar cycles. This means that the considered data set, covering 33 years of measurements, is particularly valuable and suitable to search for a possible influence of solar activity on Es layer. Table 1 shows the time interval, and the corresponding minimum and maximum activity in terms of $F_{10.7}$, of each of the three considered solar cycles.

With the aim to investigate the possible influence of solar cycle variability on Es layer, the $f_{o}$ Es and $f b$ Es values recorded between 10:00 LT and 14:00 LT were used to calculate the time series of mean values around 12:00 LT, $\overline{f o E s}_{12 \mathrm{LT}}$ and $\overline{f b E s}_{12 \mathrm{LT}}$ (black curves in Fig. 1). The few gaps present in the $\overline{f o E s}_{12 \mathrm{LT}}\left(\overline{f b E s}_{12 \mathrm{LT}}\right)$ time series, concentrated mostly in the winter months, and caused by the absence of the Es layer between 10:00 LT and 14:00 LT, were filled with the mean of the corresponding values of the previous and next day; in case the values of the previous and the next day were not available, the gap was filled with the monthly mean value. We focused our attention on the mean around 12:00 LT, because it is known that mid-latitude Es layers present a maximum of electron density right around this local time hour (i.e. Bossolasco \& Elena 1963; Pignalberi et al. 2014). Table 2 shows the occurrence percentage of the various types of Es traces, $l$ (ow), $c$ (usp) and $h$ (igh), recorded between 10:00 LT
Table 1. The months of start and end, as well as the values of minimum and maximum solar activity expressed in terms of $F_{10.7}$, are shown for each of the solar cycles 21,22 and 23 . The solar cycle 24 , which is not practically considered in this study, is included for completeness.

\begin{tabular}{|c|c|c|}
\hline $\begin{array}{l}\text { Solar } \\
\text { cycle }\end{array}$ & $\begin{array}{l}\text { Initial month-final } \\
\text { month }\end{array}$ & $\begin{array}{l}\text { Minimum } F_{10.7}-\text { maximum } \\
F_{10.7}\left(10^{-22} \mathrm{Wm}^{-2} \mathrm{~Hz}^{-1}\right)\end{array}$ \\
\hline 21 & $\begin{array}{l}\text { June 1976-September } \\
1986\end{array}$ & $72.7-207.5$ \\
\hline 22 & $\begin{array}{l}\text { September 1986-May } \\
1996\end{array}$ & 72.8-201.4 \\
\hline 23 & $\begin{array}{l}\text { May 1996-December } \\
2008\end{array}$ & $69.6-164.7$ \\
\hline 24 & December 2008- & $64.9-$ \\
\hline
\end{tabular}


Fig. 1. (a) Time series of $\overline{f o E s}_{12 \mathrm{LT}}$ values (black curve) and $\overline{f o \mathrm{Es}}(365)_{12 \mathrm{LT}}$ values (red curve), and (b) time series of $\overline{f b E s}_{12 \mathrm{LT}}$ values (black curve) and $\overline{f b E s}(365)_{12 \mathrm{LT}}$ values (red curve), for the period January 1976-December 2009.

and 14:00 LT, for the whole data set from January 1976 to December 2009.

Once the $\overline{f o E s}_{12 \mathrm{LT}}$ and $\overline{f b E s}_{12 \mathrm{LT}}$ time series were generated, the time series of the corresponding 365 day running means, $\overline{f o \mathrm{Es}}(365)_{12 \mathrm{LT}}$ and $\overline{f b \mathrm{Es}}(365)_{12 \mathrm{LT}}$, were also generated (red curves in Fig. 1). 
M. Pezzopane et al.: On the influence of solor activity on the mid-latitude sporadic E layer

Table 2. The occurrence percentage of the various types ( $1, \mathrm{c}$ and $\mathrm{h}$ ) of Es is given for each hour from 10:00 LT to 14:00 LT, for the whole data set from January 1976 to December 2009.

\begin{tabular}{lccccc}
\hline \hline Hour (LT) & Total ionograms & Ionograms with Es & Es type "l” & Es type "c" & Es type “ $h "$ \\
\hline $10: 00$ & 11,650 & 9142 & $1830(\sim 20 \%)$ & $6411(\sim 70 \%)$ & $901(\sim 10 \%)$ \\
$11: 00$ & 11,757 & 8908 & $2277(\sim 26 \%)$ & $5763(\sim 65 \%)$ & $868(\sim 9 \%)$ \\
$12: 00$ & 11,915 & 8364 & $2683(\sim 32 \%)$ & $4785(\sim 57 \%)$ & $896(\sim 11 \%)$ \\
$13: 00$ & 11,967 & 7813 & $2797(\sim 36 \%)$ & $3916(\sim 50 \%)$ & $1100(\sim 14 \%)$ \\
$14: 00$ & 11,959 & 7515 & $2684(\sim 36 \%)$ & $3454(\sim 46 \%)$ & $1377(\sim 18 \%)$ \\
\hline
\end{tabular}
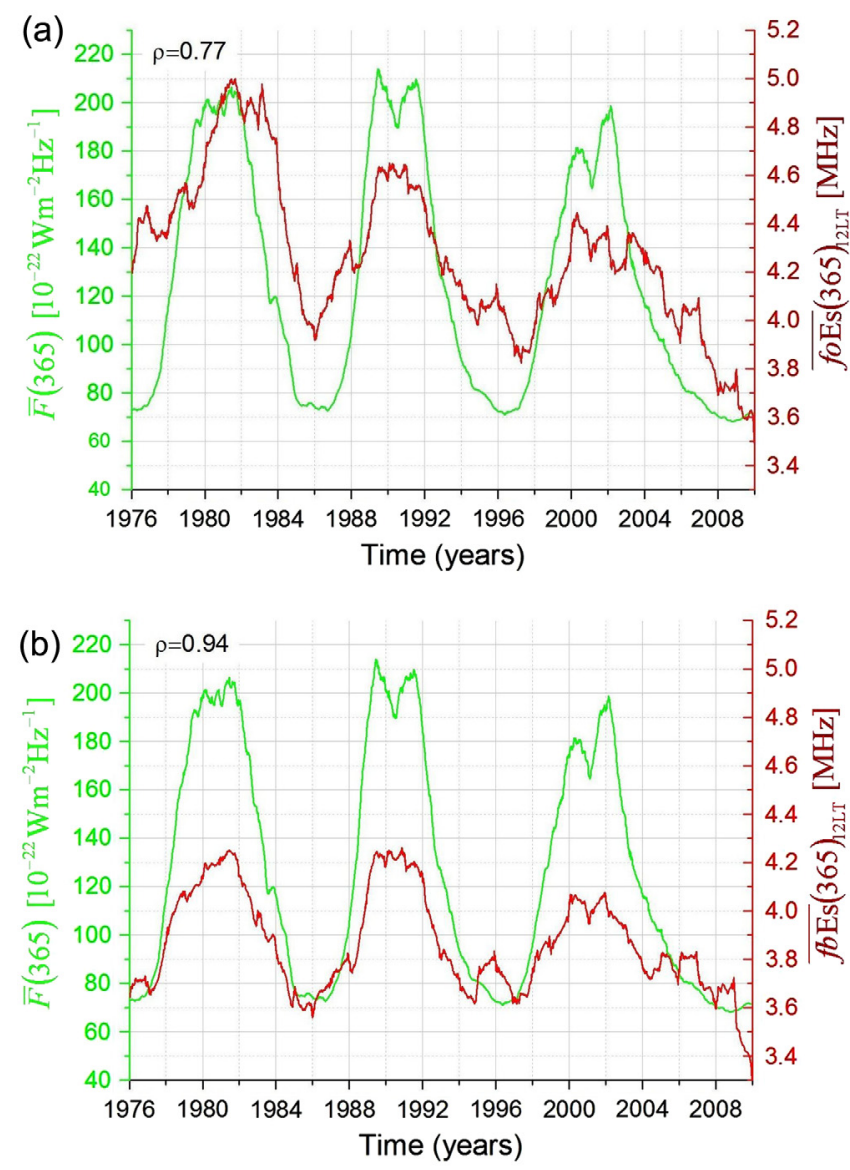

Fig. 2. Comparison (a) between $\bar{F}(365)$ (green curve) and $\overline{f o E s}(365)_{12 L T}$ (red curve) and (b) between $\bar{F}(365)$ (green curve) and $\overline{f b E s}(365)_{12 \mathrm{LT}}$ (red curve), between January 1976 and December 2009. In the upper left corner, the corresponding correlation coefficients are shown.

Our analyses, which are essentially based on $\overline{f o E s}(365)_{12 \mathrm{LT}}$ and $\overline{f b \mathrm{Es}}(365)_{12 \mathrm{LT}}$, and on the 365 days running mean of the daily values of $F_{10.7}, \bar{F}(365)$, are then much less rough than those carried out by Bossolasco \& Elena (1963), and Maksyutin et al. (2001), which are based on yearly averages of $f o$ Es and the sunspot number.

The methods used to investigate the possible role played by the quasi 11-years solar cycle activity on Es layer are three: (a) a comparison between $\bar{F}(365)$ and $\overline{f o \mathrm{Es}}(365)_{12 \mathrm{LT}}\left(\overline{f b \mathrm{Es}}(365)_{12 \mathrm{LT}}\right)$ for the whole considered period (Fig. 2), performing at the same time a linear regression analysis on the corresponding long-term trends (Fig. 3); (b) a linear regression analysis to compare $\bar{F}(365)$ with $\overline{f o E s}(365)_{12 \mathrm{LT}}\left(\overline{f b \mathrm{Es}}(365)_{12 \mathrm{LT}}\right)$ for each single solar cycle (21, 22 and 23), distinguishing also between the corresponding ascending and descending phase (Fig. 4); (c) a Lomb-Scargle
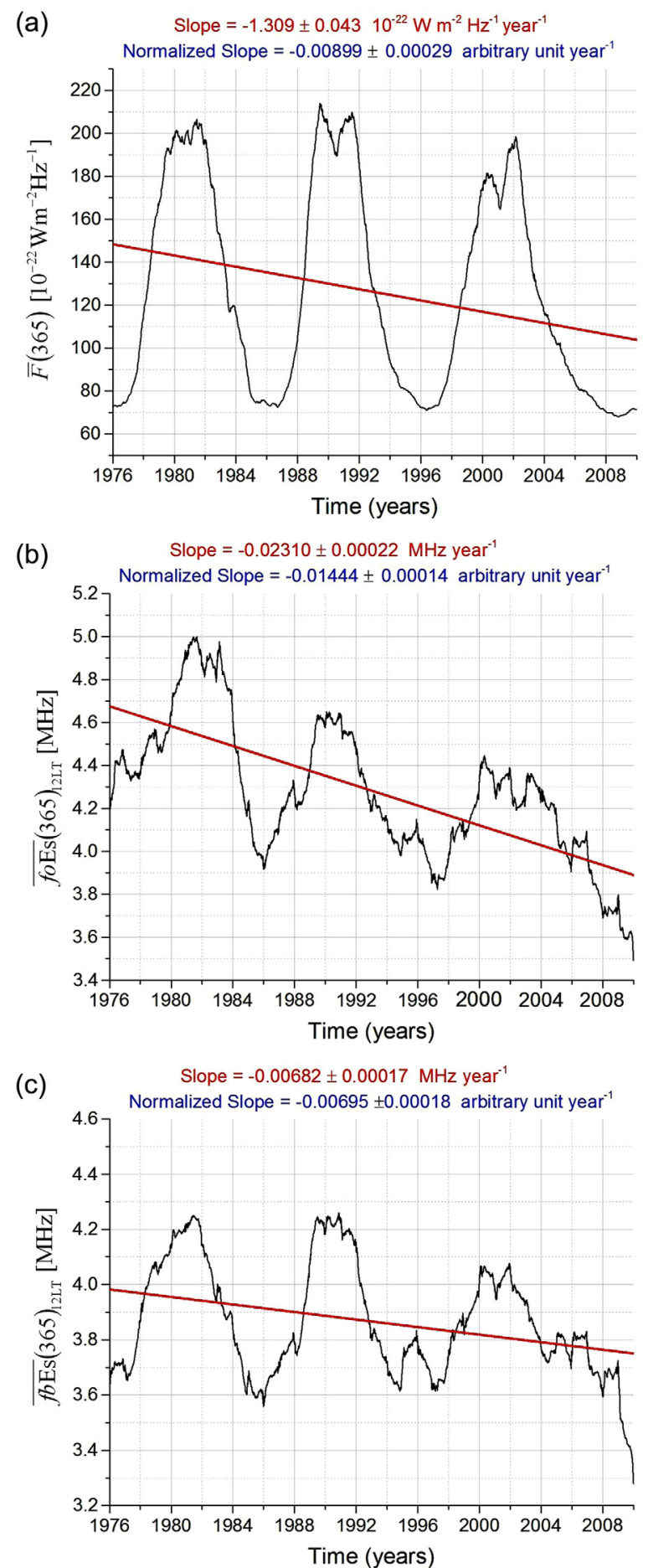

Fig. 3. Long-term trends of (a) $\bar{F}(365)$, (b) $\overline{f o E s}(365)_{12 \mathrm{LT}}$ and (c) $\overline{f b E s}(365)_{12 \mathrm{LT}}$ between January 1976 and December 2009. The red line in each panel shows the corresponding linear fit. The slope of the red line and the slope of the normalized fit are indicated at the top of each panel in red and blue, respectively. 
(a)

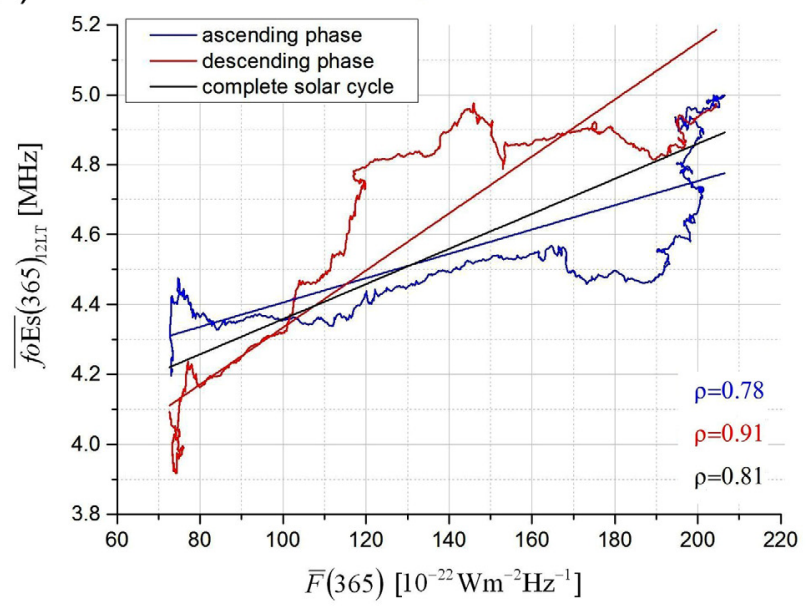

(b)

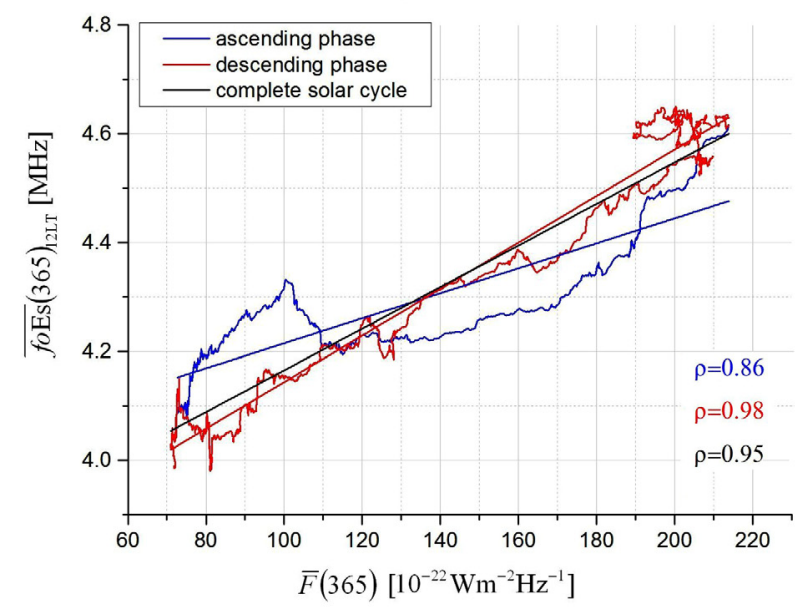

(c)



(d)

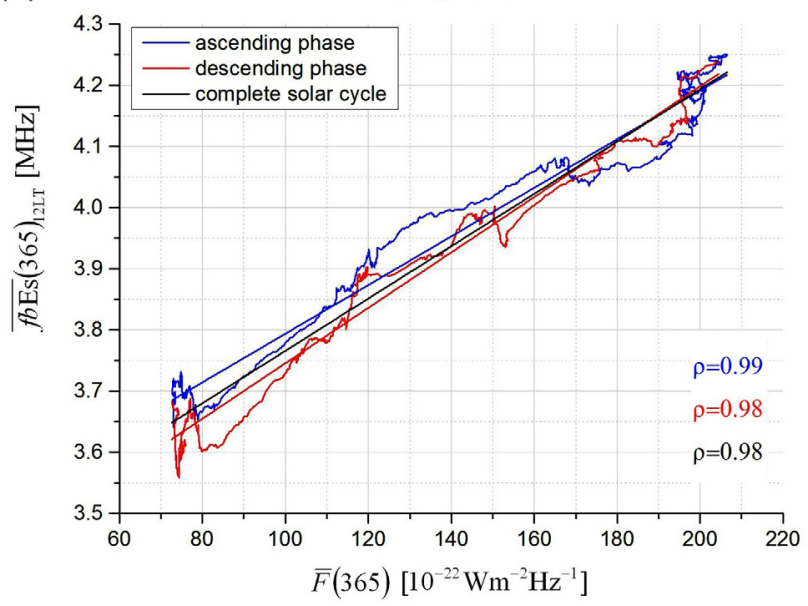

(e)



(f)

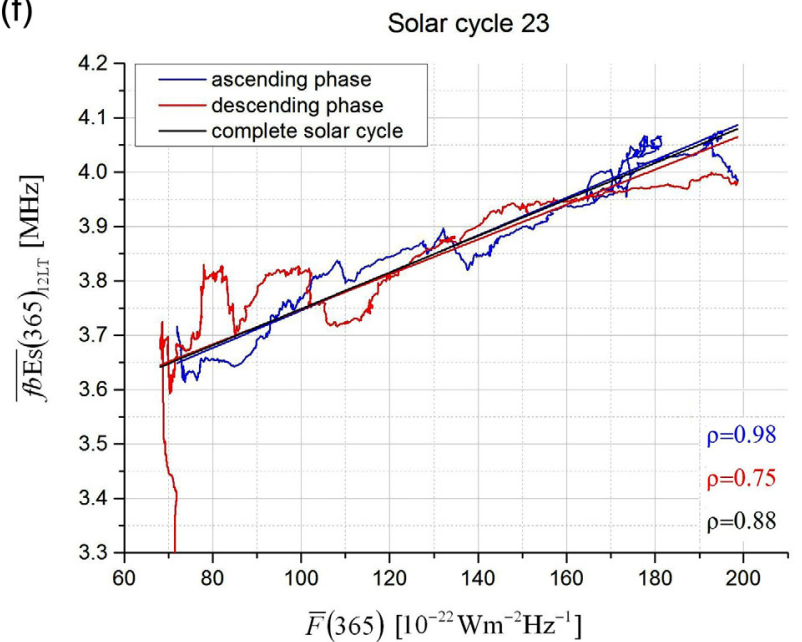

Fig. 4. On the left column, $\overline{f o E s}(365)_{12 L \mathrm{~T}}$ is plotted against $\bar{F}(365)$ for solar cycles (a) 21 , (b) 22 and (c) 23 . On the right column, $\overline{f b \operatorname{Es}}(365)_{12 L T}$ is plotted against $\bar{F}(365)$ for solar cycles (d) 21, (e) 22 and (f) 23. The linear fit for the complete solar cycle is shown in black. The ascending and descending phases of each solar cycle along with the corresponding linear fit are shown in blue and red, respectively. In the lower right corner of each plot, the corresponding correlation coefficients are shown.

analysis both on the $\overline{f o E s}_{12 \mathrm{LT}}$ and $\overline{f b E s}_{12 \mathrm{LT}}$ time series and on the $\overline{f o \mathrm{Es}}(365)_{12 \mathrm{LT}}$ and $\overline{f b \mathrm{Es}}(365)_{12 \mathrm{LT}}$ time series, in order to highlight which periodicities are embedded in the $f o$ Es and $f b$ Es time series. The corresponding periodograms are shown in Figure 5.

\section{Discussion and conclusions}

From the visual inspection of ${\overline{f o \mathrm{Es}_{12 \mathrm{LT}}}}_{\text {and }} \overline{\mathrm{fbEs}}_{12 \mathrm{LT}}$ trends (black curves in Fig. 1), an annual oscillation of $f o$ Es and $f b$ Es clearly emerges (also highlighted by the left periodograms of 

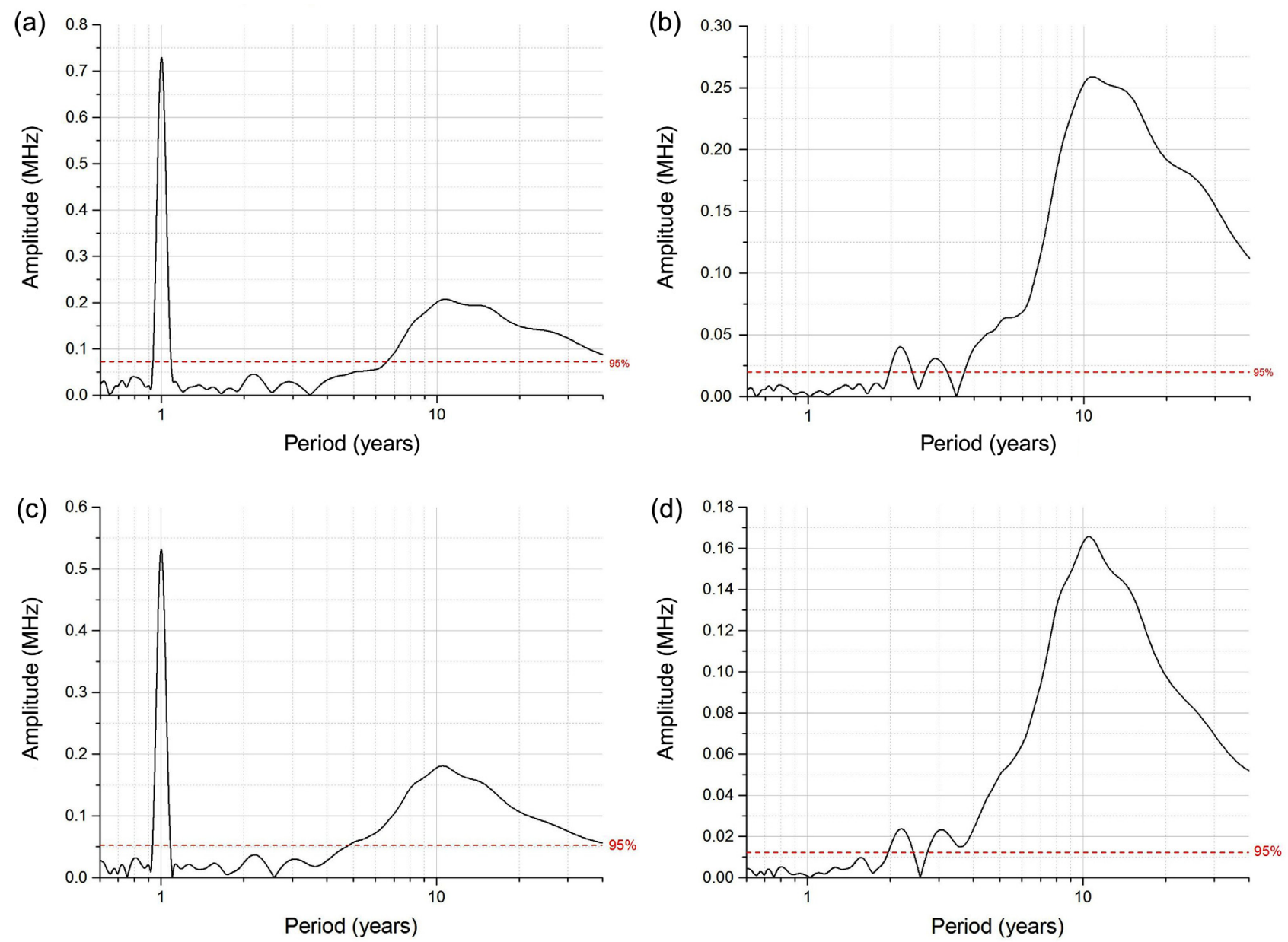

Fig. 5. Lomb-Scargle periodograms of (a) $\overline{f o E s}_{12 \mathrm{LT}}$, (b) $\overline{f o \mathrm{Es}}(365)$ dashed lines mark the $95 \%$ confidence level.

(c) $\overline{f b E s}_{12 \mathrm{LT}}$ and (d) $\overline{f b \mathrm{Es}}(365)_{12 \mathrm{LT}}$ time series. The red horizontal

Fig. 5). However, although less evident, also a wave-like oscillation related to the solar cycle seems to be imprinted in this time series.

In order to find a possible relationship between the solar cycle variability and $f o$ Es $(f b E s)$, the time series of $\overline{f o \mathrm{Es}}(365)_{12 \mathrm{LT}}$ and $\overline{f b \mathrm{Es}}(365)_{12 \mathrm{LT}}$ were generated; the 365 day running mean in fact acts as a low pass band filter, which eliminates the high frequencies, permitting as a consequence to better emphasize possible multi-year periodicities. Actually, the red curves in Figure 1 suggest that a possible correlation between the solar cycle activity and the values of $f o$ Es and $f b E s$ around 12:00 LT seems to be plausible.

The solar cycle influence on Es layer seems to be confirmed also from the high and statistically significant (confidence level of $95 \%$ ) value of the correlation coefficient $(\rho=0.77)$ between $\bar{F}(365)$ and $\overline{f o \mathrm{Es}}(365)_{12 \mathrm{LT}}$ (Fig. 2a), and the even higher value of the correlation coefficient $(\rho=0.94)$ between $\bar{F}(365)$ and $\overline{f b E s}(365)_{12 \mathrm{LT}}$ (Fig. 2b). Moreover, the three decreasing long-term trends of $\bar{F}(365)$, $\overline{f o \mathrm{Es}}(365)_{12 \mathrm{LT}}$ and $\overline{f b \mathrm{Es}}(365)_{12 \mathrm{LT}}$, as observed in Figure 3, suggest that on the whole the characteristics $f o$ Es and $f b$ Es follow the solar index $F_{10.7}$. With regard to the comparison between $\overline{f o E s}(365)_{12 \mathrm{LT}}$ and $\bar{F}(365)$, a greater normalized slope $(-0.01444$ vs. -0.00899$)$ indicates that, besides the solar activity, also some other physical mechanism concurs to the decrease of $f_{o}$ Es. It is interesting to highlight that the decreasing trend characterizing foEs was noticed also by
Maksyutin et al. (2001), who used a data set of three solar cycles, as we did in this work; however, it is worth noting that the two data sets are shifted of about 20 years (1955-1988 vs. 1976-2009), which underlines that this decrease is a feature that has characterized the $f o$ Es trend since more than half a century.

With regard to the comparison between $\overline{f b \mathrm{Es}}(365)_{12 \mathrm{LT}}$ and $\bar{F}(365)$, the linear fit shows that the corresponding normalized slopes $(-0.00695$ vs. -0.00899$)$ are not so different from each other, thus indicating that the decreasing long-term trend of $f b$ Es follows quite faithfully that of $F_{10.7}$, and this constitutes a further evidence in favour of the influence of solar activity on Es layer.

To investigate this feature deeper, a comparison between $\bar{F}(365)$ and $\overline{f o \mathrm{Es}}(365)_{12 \mathrm{LT}}\left(\overline{f b \mathrm{Es}}(365)_{12 \mathrm{LT}}\right)$ was carried out for each solar cycle, highlighting the different trends characterizing the corresponding ascending and descending phases. A high positive and statistically significant (confidence level of $95 \%$ ) correlation was found between $\bar{F}(365)$ and $\overline{f o E s}(365)_{12 \mathrm{LT}}$ for all the three solar cycles $\left(\rho_{21}=0.81\right.$, $\left.\rho_{22}=0.95, \rho_{23}=0.84\right)$ as well as for their corresponding ascending and descending phases $\left(\rho_{21 \text {,asc }}=0.78\right.$, $\rho_{21, \mathrm{desc}}=0.91 ; \rho_{22, \mathrm{asc}}=0.86, \rho_{22, \mathrm{desc}}=0.98 ; \rho_{23, \mathrm{asc}}=0.96$, $\rho_{23, \text { desc }}=0.77$ ) (Figs. $4 \mathrm{a}-4 \mathrm{c}$ ). Even higher correlations were found between $\bar{F}(365)$ and $\overline{f b E s}(365)_{12 \mathrm{LT}}$ for all the three solar cycles $\left(\rho_{21}=0.98, \rho_{22}=0.96, \rho_{23}=0.88\right)$ as well as for their corresponding ascending phases $\left(\rho_{21 \text {, asc }}=0.99\right.$, $\left.\rho_{22 \text {,asc }}=0.96, \rho_{23, \text { asc }}=0.98\right)$, while for the descending phases 
slightly smaller correlations than those found between $\bar{F}(365)$ and $\overline{f o \mathrm{Es}}(365)_{12 \mathrm{LT}}$ were obtained for the solar cycles 22 and 23, $\quad\left(\rho_{21, \mathrm{desc}}=0.98, \quad \rho_{22, \mathrm{desc}}=0.96, \quad \rho_{23, \mathrm{desc}}=0.75\right)$ (Figs. 4d-4f).

The very high positive correlations characterizing both the ascending and descending phases of each solar cycle indicate that both $f o$ Es and $f b$ Es follow the solar activity cycle well, and therefore they provide further important proofs in support of the influence of solar cycle variability on Es layer.

From a careful visual inspection of Figures $4 \mathrm{a}-4 \mathrm{c}$ it emerges that for solar cycles 21, 22 and 23 the descending phase trends (red curves) lie above the ascending ones (blue curves) in the ranges (100-200), (130-215) and (75-165) $10^{-22} \mathrm{Wm}^{-2} \mathrm{~Hz}^{-1}$, respectively. As the whole ranges of $F_{10.7}$ for the solar cycles 21,22 and 23 are more or less (75-205), (72-215) and (72-200) $10^{-22} \mathrm{Wm}^{-2} \mathrm{~Hz}^{-1}$, respectively, it is possible to state that the percentages for which the descending curves lie above the ascending ones are about $77 \%$, $60 \%$ and $70 \%$, respectively, indicating in general that $f o$ Es values in the descending phase are greater than those characterizing the ascending one. This circumstance suggests that $f o$ Es is affected by a sort of hysteresis phenomenon keeping "memory" of its past history and going "slowly" down towards the solar minimum phase. This feature constitutes a new and interesting finding because, as far as we know, a similar result does not appear in the existing literature. It is very difficult to now give a physical explanation of this phenomenon and we think that further studies, based on $f o$ Es data recorded in other ionospheric stations, are needed.

The apparent lack of correlation observed in the range (150-190) $10^{-22} \mathrm{Wm}^{-2} \mathrm{~Hz}^{-1}$ for solar cycles 21 (Fig. 4a) and 23 (Fig. 4c) during the descending phase, as well as during the ascending phase in the range (170-190) $10^{-22} \mathrm{Wm}^{-2} \mathrm{~Hz}^{-1}$ for solar cycle 21 (Fig. 4a), may be the signature that $f_{o}$ Es shows a certain inertia to decrease (for the descending phase) or to increase (for the ascending phase) around high levels of solar activity. Also this constitutes a new and interesting feature for which we do not yet have a physical explanation. What we can say is that the inertia of $f o$ Es to increase for large values of $F_{10.7}$ somehow reminds us of the saturation effect experienced by $f o F 2$ as the solar activity increases, but this is obviously speculative and a deeper investigation is needed.

A lack of positive correlation, during the ascending phase of solar cycle 22, is observed also in the small range (100-110) $10^{-22} \mathrm{Wm}^{-2} \mathrm{~Hz}^{-1}$, but a slow and constant increase of $f_{o} \mathrm{Es}$ can be observed in the range (110-190) $10^{-22} \mathrm{Wm}^{-2} \mathrm{~Hz}^{-1}$ (Fig. 4b). Anyway, in spite of some ranges of $F_{10.7}$ where the correlation is poor, on the whole the correlation coefficients remain rather high.

With regard to the visual inspection of Figures $4 d-4 f$ the following considerations can be done: (a) for the solar cycle 21 the ascending phase trend (blue curve) lies above the descending one (red curve) in the range (75-170) $10^{-22} \mathrm{Wm}^{-2} \mathrm{~Hz}^{-1}$, which corresponds to a percentage of about $66 \%$; therefore, this situation is practically reverse to that observed for $f_{o}$ Es (Fig. 4a); (b) the situation for the solar cycle 22 is quite similar to that observed for $f_{o}$ Es (Fig. 4b) with a descending phase trend (red curve) lying above the ascending one (blue curve) in the range (110-190) $10^{-22} \mathrm{Wm}^{-2} \mathrm{~Hz}^{-1}$, which corresponds to a percentage of about $56 \%$; (c) a very tangled situation is observed for the solar cycle 23 for which it is not possible to distinguish a long range of $F_{10.7}$ for which the ascending (descending) phase clearly prevails on the descending (ascending) one.

Thus, except for the solar cycle 22, and differently from $f o$ Es, $f b$ Es does not seem to be subjected to a hysteresis phenomenon.

Finally, in order to better emphasize possible multi-year periodicities, the Lomb-Scargle analysis was applied both on $\overline{f o E s}_{12 \mathrm{LT}}$ and $\overline{f_{o \mathrm{Es}}}(365)_{12 \mathrm{LT}}$ time series, as well as on $\overline{f b E s}_{12 \mathrm{LT}}$ and $\overline{f b \mathrm{Es}}(365)_{12 \mathrm{LT}}$ time series. The corresponding periodograms (Figs. 5a, 5b and 5c, 5d) show the presence of a statistically significant (confidence level of 95\%) peak at about 11 years, indicating unequivocally the signature of the influence of the quasi 11-years solar cycle variability on the ionospheric characteristics $f o$ Es and $f b \mathrm{Es}$, hence on Es layer.

Concerning the physical explanation of the results achieved in this study, some preliminary considerations are needed. The molecular ions $\left(\mathrm{O}_{2}^{+}\right.$and $\left.\mathrm{NO}^{+}\right)$and the long-lived metallic ions $\left(\mathrm{Fe}^{+}\right.$and $\left.\mathrm{Mg}^{+}\right)$are the two main elements that must be considered when we talk about Es layers, because the former concur to the maximum electron density and thickness of Es layer and the latter contribute essentially to its formation (Harper et al. 1975).

With regard to the metallic ions, even though these are essentially produced by meteoric shower activity, there is also another important aspect that should be taken into account, that is that they can be also generated indirectly by photoionization (Withers et al. 2008). This means that the long-lived metallic ions, as on the other hand is certainly true for the molecular ions, have also a component of solar origin, and therefore their concentrations depend also on the radiation flux coming from the Sun. This implies that also the density of free electrons, which follow the molecular and metallic ions by moving along the field lines to maintain charge neutrality (Rishbeth \& Garriott 1969), is expected to vary during the solar cycle variability. This feature would explain why to solar activity variations may correspond changes of the free electrons related to molecular ions, thus determining variations of the maximum frequency reflected by the Es layer, and why to solar activity variations may correspond changes of the free electrons related to metallic ions, which determine changes of the blanketing frequency.

These considerations are likely to give also an explanation for the very similar trends observed in Figures $1-3$ and 5 and may justify: (a) the high positive and statistically significant correlations between the solar activity (in terms of $\bar{F}(365)$ ) and the Es layer (in terms of $\overline{f_{o \mathrm{Es}}}(365)_{12 \mathrm{LT}}$ and $\left.\overline{f b E s}(365)_{12 \mathrm{LT}}\right)$ which are found considering the three solar cycles all together and each solar cycle with its ascending and descending phases; (b) the clear peak emerging at quasi 11-years from the Lomb-Scargle periodograms.

The semidiurnal tides, triggered mainly by the stratospheric heating due to the absorption of UV solar radiation by ozone, could represent a further possible physical explanation of the results achieved in this study. This means that the solar cycle is expected to have some impact on the semidiurnal tides' amplitude, because the UV variations, occurring during the solar activity cycle, can modify the stratospheric heating (Vial 1993).

From an investigation performed on a time interval of more than 4 years, covering a period of maximum and decreasing solar activity, it has emerged that the variability of the amplitudes of the semidiurnal tides decreased with decreasing solar activity, thus suggesting a positive correlation between the 
solar activity and the variability of the semidiurnal tide (Pancheva et al. 2003).

Moreover, Cooper (1982) found that, over a sunspot cycle, a UV variation of $20 \%$ would result in a $12 \%$ change in the semidiurnal tide amplitude.

In the light of these considerations, and considering that the wind-shear theory is the most accredited in explaining the midlatitude Es layer formation (Whitehead 1989; Mathews 1998), the results described in this paper could be also explained by invoking the solar cycle UV variations which modulate the stratospheric warming. In fact, it is reasonable to infer that the amplitude of the semidiurnal tides triggered by the stratospheric warming is expected to increase or decrease during periods of increasing or decreasing solar activity; this concurs more or less effectively, through the wind-shear mechanism, which compels the long-lived metallic ions to converge into thin plasma layers, to the formation of more or less dense Es layers. This reasoning, if we think about the physical meaning of $f b \mathrm{Es}$, the numerical values of which express the level of transparency of the Es layer, and hence how much dense it is, could explain why the correlation coefficients between the ionospheric characteristic $f b E s$ and the solar activity (see Figs. $2 \mathrm{~b}$ and $4 \mathrm{~d}-4 \mathrm{f}$ ) are almost always greater than those related to $f_{o}$ Es (see Figs. $2 \mathrm{a}$ and $4 \mathrm{a}-4 \mathrm{c}$ ). This indicates that $f b$ Es is more suitable than $f o E s$ in emphasizing the signature of the influence of the solar cycle variability on Es layer.

As it was mentioned in the Introduction, although the influence of solar activity on Es layer has already been investigated by many authors (Bossolasco \& Elena 1963; Kotadia 1969; Baggaley 1984; Whitehead 1989; Maksyutin et al. 2001; Pietrella \& Bianchi 2009; Pietrella et al. 2014), it is still a topic of debate. This is why we think that this work could be important, because the analyses shown in this paper, which are surely more refined than the previous studies on the subject, show beyond any doubt that the daytime Es layer is positively correlated with the solar activity, a result which is an unequivocal proof in support of the influence of solar activity on Es layer.

Acknowledgements. The authors are sincerely grateful to the unknown referees for their useful comments and suggestions which contributed to improve the quality of the paper. We also wish to thank the NOAA's National Geophysical Data Center for making the $F_{10.7}$ daily data available at the following ftp address: $\mathrm{ftp} / / /$ ftp.ngdc.noaa.gov/STP/space-weather/solar-data/solar-features/solarradio/noontimeflux/penticton/penticton_observed/listings/listing_ drao_noontime-flux-observed_daily.txt. The editor thanks Jan Laštovička and an anonymous referee for their assistance in evaluating this paper.

\section{References}

Axford, W.I. The formation and vertical movement of dense ionized layers in the ionosphere due to neutral wind shears. J. Geophys. Res., 68, 769-779, 1963.

Baggaley, W.J. Three solar cycles of day-time southern hemisphere Es activity. J. Atmos. Terr. Phys., 46, 207-210, 1984.

Barry Research Corporation. VOS-1A User Manual, Palo Alto, California, USA, 1975.

Bibl, K., and B.W. Reinisch. The universal digital ionosonde. Radio Sci., 13, 519-530, 1978, DOI: 10.1029/RS013i003p00519.

Bossolasco, M., and A. Elena. Sporadic E-layer ionization and sunspot cycle. Geofis. Pura Appl., 56, 142-149, 1963.

Chimonas, G. Enhancement of sporadic E by horizontal transport within the layer. J. Geophys. Res., 76, 4578-4586, 1971.

Chimonas, G., and W.I. Axford. Vertical movement of temperatezone sporadic E layers. J. Geophys. Res., 73, 111-117, 1968.
Cooper, N.S. Inferring solar UV variability from the atmospheric tide. Nature, 296, 131-132, 1982.

Haldoupis, C. A tutorial review on Sporadic E layers. In Aeronomy of the Earth's atmosphere-ionosphere, Springer Dordrecht Heidelberg London New York, IAGA Book Series 2, 381-394, 2011.

Haldoupis, C. Midlatitude Sporadic E layers. A typical paradigm of atmosphere-ionosphere coupling. Space Sci. Rev., 168, 441-461, 2012, DOI: 10.1007/s11214-011-9786-8.

Haldoupis, C., and D. Pancheva. Planetary waves and midlatitude sporadic E layers: strong experimental evidence for a close relationship. J. Geophys. Res., 107, SIA 3-1-SIA 3-6, 2002. DOI: 10.1029/2001JA000212.

Haldoupis, C., D. Pancheva, and N.J. Mitchell. A study of tidal and planetary wave periodicities present in midlatitude sporadic E layers. J. Geophys. Res., 109, A02302, 2004, DOI: 10.1029/2003JA010253.

Harper, R.M., R.H. Wand, and J.D. Whitehead. Comparison of Arecibo E-region data and sporadic E theory: a measurement of the diffusion coefficient. Radio Sci., 10, 357, 1975.

Kotadia, K.M. Sporadic-E ionization over Ahmedabad through the half solar cycle 1954-1957. J. Atmos. Terr. Phys., 31, 1137-1146, 1969.

Lastovicka, J., J. Boska, D. Buresova, and D. Kouba. High historical values of foEs - reality or artefact?". J. Atmos. Sol. Terr. Phys., 74, 51-54, 2012.

MacDougall, J.W. $110 \mathrm{~km}$ neutral zonal wind patterns. Planet. Space Sci., 22, 545-558, 1974.

Maksyutin, S.V., O.N. Sherstyukov, and A.N. Fahrutdinova. Dependence of sporadic-E layer and lower thermosphere dynamics on solar activity. Adv. Space Res., 27, 1265-1270, 2001.

Mathews, J.D. Sporadic E: current views and recent progress. J. Atmos. Sol. Terr. Phys., 60, 413-435, 1998.

Pancheva, D., N. Mitchell, H. Middleton, and H. Muller. Variability of the semidiurnal tide due to fluctuations in solar activity and total ozone. J. Atmos. Sol. Terr. Phys., 65, 1-19, 2003.

Pietrella, M., and C. Bianchi. Occurrence of sporadic-E layer over the ionospheric station of Rome: analysis of data for thirty-two years. Adv. Space Res., 44, 72-81, 2009,

DOI: 10.1016/j.asr.2009.03.006.

Pietrella, M., M. Pezzopane, and C. Bianchi. A comparative sporadic-E layer study between two mid-latitude ionospheric stations. Adv. Space Res., 54, 150-160, 2014 DOI: $10.1016 /$ j.asr.2014.03.019.

Piggott, W.R., and K. Rawer. URSI handbook of ionogram interpretation and reduction, US Department of Commerce, National Oceanic and Atmospheric Administration, Environmental Data Service, Asheville, NC, 326, Report UAG 23, 1972.

Pignalberi, A., M. Pezzopane, and E. Zuccheretti. Sporadic E layer at mid-latitudes: average properties and influence of atmospheric tides. Ann. Geophys., 32, 1427-1440, 2014, DOI: 10.5194/angeo-32-1427-2014.

Pignalberi, A., M. Pezzopane, and E. Zuccheretti. A spectral study of the mid-latitude sporadic E layer characteristic oscillations comparable to those of the tidal and the planetary waves. J. Atmos. Sol. Terr. Phys., 122, 34-44, 2015, DOI: $10.1016 /$ j.jastp.2014.10.017.

Rice, D.D., J.J. Sojka, J.V. Eccles, J.W. Raitt, J.J. Brady, and R.D. Hunsucker. First results of mapping sporadic E with a passive observing network. Space Weather, 9, S12001, 2011, DOI: $10.1029 / 2011$ SW000678.

Rishbeth, H., and O.K. Garriott. Introduction to ionospheric physics, Academic Press, New York, USA, 331, 1969.

Romano, V., S. Pau, M. Pezzopane, E. Zuccheretti, B. Zolesi, G. De Franceschi, and S. Locatelli. The electronic space weather upper atmosphere (eSWua) project at INGV: advancements and state of the art. Ann. Geophys., 26, 345-351, 2008, DOI: 10.5194/angeo-26-345-2008.

Szuszczewicz, E.P., R.G. Roble, P.J. Wilkinson, and R. Hanbaba. Coupling mechanisms in the lower ionospheric - thermospheric 
system and manifestations in the formation and dynamics of intermediate descending layers. J. Atmos. Terr. Phys., 57, 1483-1496, 1995.

Tsunoda, R., M. Yamamoto, K. Igarashi, K. Hocke, and S. Fukao. Quasi-periodic radar echoes from midlatitude sporadic E and role of the 5-day planetary wave. Geophys. Res. Lett., 25, 951-954, 1998

Vial, F. Causes of tidal variability. In: E.V. Thrane, T.A. Blix, D.C Fritts, Editors, Coupling processes in the lower and middle atmosphere, Springer Science+Business Media Dordrecht, Netherlands, NATO ASI, 387, 137-151, 1993.

Whitehead, J.D. The formation of the sporadic-E layer in the temperate zones. J. Atmos. Terr. Phys., 20, 49-58, 1961.

Whitehead, J.D. Production and prediction of sporadic E. Rev. Geophys. Space Phys., 8, 65-144, 1970.
Whitehead, J.D. Recent work on mid-latitude and equatorial sporadic-E. J. Atmos. Terr. Phys., 51, 401-424, 1989.

Wilkinson, P.J., E.P. Szuszczewicz, and R.G. Roble. Measurements and modelling of intermediate, descending, and sporadic layers in the lower ionosphere: results and implications for global-scale ionospheric- thermospheric studies. Geophys. Res. Lett., 19, 95-98, 1992.

Withers, P., M. Mendillo, D.P. Hinson, and K. Cahoy. Physical characteristics and occurrence rates of meteoric plasma layers detected in the Martian ionosphere by the Mars Global Surveyor Radio Science Experiment. J. Geophys. Res., 113, A12314, 2008, DOI: $10.1029 / 2008 J A 013636$.

Zuccheretti, E., G. Tutone, U. Sciacca, C. Bianchi, and B.J. Arokiasamy. The new AIS-INGV digital ionosonde. Ann. Geophys. Italy, 46, 647-659, 2003.

Cite this article as: Pezzopane M, Pignalberi A \& Pietrella M. On the influence of solar activity on the mid-latitude sporadic E layer. $J$. Space Weather Space Clim., 5, A31, 2015, DOI: 10.1051/swsc/2015031. 